\title{
La diferencia léxica entre los jóvenes tapatíos y los jóvenes madrileños
}

DOI: $10.32870 /$ mycp.v8i26.273

Daisuke Kishi

\section{Introducción}

$\mathrm{E}$ 1 origen del presente trabajo proviene de nuestro estudio sobre la "Variación léxica según el sexo en el lenguaje hablado de los jóvenes tapatíos" (Kishi, 2002), en el cual se puede adquirir cierto conocimiento sobre la norma lingüística del habla de los jóvenes tapatíos con respecto a algunos vocablos relativos a la apariencia y características físicas. Aunque estos días haya una globalización lingüística gracias al desarrollo sorprendente de los medios de comunicación, tales como el uso del Internet y la difusión de todo tipo de programas por la televisión: noticias, telenovelas, canciones pop, deportes y otras aficiones, entre otros, no podemos olvidarnos de la regionalización lingüística. De hecho, a partir de 1492 inició la diversificación de la lengua española. Al hablar de esta variación regional o dialectal, es importante considerar otros puntos de vista. En el aspecto sociolingüístico, de acuerdo con el sexo, edad y nivel sociocultural, dentro del "español" se puede encontrar una variación o preferencia; en algunos casos, incluso, se puede presentar más variación sociolingüística que dialectal.

Moreno de Alba hizo un estudio sobre la diferenciación entre el español de Es-

Profesor-investigador del Departamento de Estudios del Pacífico de la Universidad de Guadalajara. paña y el de América, el cual es uno de los trabajos más importantes a nivel léxico; en ese trabajo se puede tener una visión panorámica sobre la variación léxica que existe en ambos continentes, pero se limita al aspecto dialectal (Moreno, 1992). En el plano sociolingüístico, nadie podrá negar que Labov ${ }^{1}$ sea uno de los sociolingüistas más importantes. Asimismo, hay valiosos estudios sociolingüísticos hispánicos que han hecho grandes investigadores y estudiosos como Silva-Corvalán, López Morales, Bentivoglio, Ávila y muchos más. Sin embargo, el enfoque de la mayoría de los estudios mencionados se refiere únicamente a "un habla", pero no comparativo de una con otra. De ahí que haya surgido nuestro proyecto de investigación sobre la "diferencia léxica entre los jóvenes tapatíos y los jóvenes madrileños", el cual fue avalado y financiado por la Secretaría Académica del Centro Universitario de Ciencias Sociales y Humanidades de la Universidad de Guadalajara, en el marco del Programa 07.1: Fortalecimiento a la Investigación 2004.

\section{El propósito del trabajo y la metodología}

La variable social incluye varios factores, en especial sexo, edad y estrato social. En nuestro caso, con motivo de analizar de manera comparativa los datos que se obtuvieron en Guadalajara y Madrid, se 
tomó en cuenta únicamente la variable de sexo para someternos a investigar sobre la posible variación léxica en los jóvenes tapatíos y madrileños en relación con algunos rasgos físicos de una persona. ${ }^{2}$ Así que el corpus -indudablemente- refleja en ambas ciudades algunas características del habla juvenil, aunque no creemos que dicho lenguaje esté muy alejado del lenguaje coloquial estándar o de otras generaciones mayores. Con respecto a la variable de estrato social o nivel sociocultural, ya que la mayoría de los informantes son estudiantes universitarios, se podrá suponer teóricamente que pertenecen al nivel sociocultural medio-alto.

Los datos que utilizamos para conocer el habla juvenil de Guadalajara fueron recopilados en un estudio anterior (Kishi, 2002). Para obtener los datos referentes al habla juvenil de Madrid, se aplicó la misma metodología. Las entrevistas se llevaron a cabo durante los días 26 y 28 de octubre de 2004 en varias facultades de la Universidad Complutense de Madrid. Es importante mencionar que en la mayoría de los casos la calidad de la grabación magnetofónica resultó mala por los ruidos o la acústica inadecuada, puesto que a causa del tiempo limitado nos vimos obligados a escoger lugares ruidosos como la cafetería, el pasillo o la entrada del edificio. En este sentido, los informantes dijeron palabras o partes del discurso que fueron incomprensibles; no creemos que, sin embargo, la pequeña fluctuación de frecuencia del uso de las palabras sea de importancia en este tipo de investigaciones. En cuanto al cuestionario, algunos ítems fueron modificados. En el ítem 6 que pregunta: "Cuando uno tiene piel de color claro [...] Cuando la tiene obscura, ¿cómo le llamarías?”, algunos madrileños contestaron "negro" en vez de "moreno" o alguna otra palabra equiva- lente, seguramente por una confusión con el color de piel relacionada con la raza; por eso después preguntamos: "Cuando la tiene obscura como algunos andaluces [...]." De la misma manera, en el ítem 11 evitamos el uso del nombre de Amanda Miguel para designar a alguien que tiene el pelo muy "rizado", ya que David Bisbal es un cantante español más conocido entre los jóvenes madrileños.

Por otro lado, escogimos treinta jóvenes madrileños (quince hombres y quince mujeres) nacidos y crecidos en Madrid. La edad de los informantes varió entre dieciocho y veintiocho años que coincide casi totalmente con la de los tapatíos. También intentamos escoger diferentes carreras, como sucedió en la investigación de Guadalajara. Todo esto hizo posible que la distribución de los informantes de ambas ciudades fuera equitativa y que el análisis comparativo fuera más científico.

\section{El análisis de los datos}

\section{1. /desnudo/}

Según los datos obtenidos, la mayoría de los informantes tapatíos (68\%), trece hombres y ocho mujeres usó el vocablo académico "desnudo"; también los madrileños lo usaron con una frecuencia similar (62.50\%). En Guadalajara se registró "encuerado"3 en $29 \%$ de los hablantes de ambos sexos: cuatro hombres y cinco mujeres, cuyo uso es algo común en esta región. En cambio, en Madrid no hubo ninguna incidencia con dicho vocablo; el único caso registrado con el mismo lexema fue "en cueros"; más bien, en esta zona $31.25 \%$ de los jóvenes prefirió usar las expresiones "en bolas" y "en pelotas", cuya tendencia fue predominante en el habla masculina - las hablantes madrileñas evitaron usar dichas palabras-,

MÉXICO YLACUENCADEL PACÍFICO 167
ol. 8, núm. 26 / septiembre-diciembre de 2005167 
ya que en España "bolas" y "pelotas" se refieren como argot a "testículos" o "cojón" (León, 1984: 40 y 122).

En Guadalajara los hombres usaron "desnudo" con más frecuencia (62\%) que las mujeres (38\%), cuyo resultado nos pareció menos verosímil, pues en general las mujeres prefieren el uso académico o normativo. Sobre este aspecto la cifra obtenida del habla madrileña fue más convincente; el mencionado término académico fue totalmente predominante en las mujeres (92.86\%), mientras que los hombres lo usaron menos (38.89\%).

\section{2. /mojado/}

En Guadalajara fue más frecuente el uso de "mojado" (58\%) que el de "empapado" (42\%). En Madrid la frecuencia de ambas palabras fue diferente: "empapado" obtuvo $47.37 \%$ y "mojado" solamente $21.05 \%$, situación que era muy probable, como lo admite Moliner (Moliner, 1979b: 1081).

Entre los hombres y las mujeres de Guadalajara no hubo ninguna preferencia con los vocablos arriba mencionados; en Madrid sí se presentó cierta variación según el sexo; es decir, "mojado" fue más usado por los hombres (28.57\%) que por las mujeres (11.76\%), mientras que las mujeres prefirieron más el uso informal de "empapado" (64.70\%) que los hombres (33.33\%). También, es interesante mencionar que hubo seis casos de "calado" o "calao"4 y cuatro casos de "sopa", por ejemplo: "como una sopa" y "hecho una sopa".

\section{3. /sucio/}

En este ítem hubo variedad léxica en Guadalajara. A pasar del polimorfismo que se presentó, la mayoría de los informantes (62\%) prefirió el uso estándar de "sucio". Después le siguió en importancia "mugroso". Encontramos tan sólo dos casos de "engrasado" y otro similar: "lleno de grasa". Estas respuestas, sin embargo, no fueron irregulares ni ilógicas, porque en la pregunta 3 del cuestionario se dijo: "alguien estaba trabajando en un taller para arreglar mi carro". Algunos madrileños interpretaron el mismo significado de dicha pregunta, pero la incidencia de esta frecuencia fue más alta; es decir, se registraron seis casos de "manchado" y dos de "pringado" o "pringao". De todas maneras, el calificativo más común en los madrileños también fue "sucio" (60\%). Otra observación interesante, desde el punto de vista regional, quizá sea el uso de "guarro" o "guarra" de cuatro informantes madrileños: "está en guarra", ${ }^{5}$ aunque dicho vocablo prácticamente se desconoce en México. En cambio, tres informantes tapatíos usaron un vocabulario relacionado con los animales: "marrano", "puerco" y "oler a chivo".

\section{4. /sano/}

En el habla madrileña la palabra predominante fue "sano" (53.66\%), y le siguió en importancia el adjetivo "saludable" (26.83\%). En Guadalajara el uso de ambas palabras resultó más o menos parejo: $47 \%$ para "saludable" contra 41\% para "sano", aunque dicha variación léxica quizá se deba a la diferencia de la conciencia lingüística de los informantes. Como otros ejemplos podemos citar lo siguiente: un informante tapatío usó el adjetivo "fuerte"; las expresiones con "roble": "tiene una salud de roble o hierro"; "tiene salud de hierro" en tres informantes madrileños probablemente corresponde a dicho uso tapatío. En forma vulgar dos madrileños expresaron que "está a/de puta madre", 
mientras que un tapatío empleó "chingón". ${ }^{6}$ Estas diferencias, aunque con pocas incidencias, parecen reflejar el ambiente cultural.

El uso de las palabras predominantes como "sano" y "saludable" en Guadalajara puede ser más o menos equitativo, mientras que en Madrid el habla femenina prefiere "saludable", porque hubo seis incidencias con las madrileñas, y los hombres no mencionaron ninguna.

\section{5. /cansado/}

Aunque en este ítem hubo bastante variación léxica, la mayoría de los informantes tapatíos prefirió el uso académico "cansado" (56\%). Le siguen "agotado" y "estresado" (7\%, respectivamente). En Madrid se registró "cansado" con una cifra porcentual menor que en Guadalajara (38.89\%), pero "agotado" tuvo más frecuencia (19.44\%). De todos modos, se puede decir que en ambas ciudades la tendencia es similar.

La frecuencia de las palabras mencionadas resultó prácticamente equitativa en las dos ciudades. Entre otros vocablos registrados, realmente encontramos pocas palabras malsonantes: "madreado" de un tapatío y "está hecho una mierda" de un madrileño.

\section{6. /blanco/-/moreno/-/rubio/}

Antes de analizar estos tres vocablos, debemos tomar en cuenta que el color de la piel y el pelo de los seres humanos están íntimamente relacionados. En la tierra tapatía el uso de "blanco" predominó (58\%). Nos parece importante, sin embargo, enterarnos de que la forma normativa mexicana "güero"7 o "güerito" alcanzó $42 \%$ cuya cifra es confirmada por el estudio de Moreno de Alba, quien encontró que dicho vocablo se desconoce en Madrid y en las principales ciudades hispanoamericanas. En Madrid la palabra predominante también fue "blanco", "blanquito" o "blanquecino" (61.90\%). Es un poco sorprendente que le haya seguido "pálido" o "paliducho" (33.33\%), pero hay una diferencia entre "blanco" y "pálido"; éste se refiere al estado "más blanco que blanco". ${ }^{8}$ También hubo dos casos de "albino", ${ }^{9}$ cuyo vocablo no se registró en Guadalajara. La variable sexo no fue importante ni en Madrid ni en Guadalajara.

La palabra "moreno" se refiere a color oscuro tanto de la piel como el pelo de una persona (RAE, 2001: 1537-1538). La respuesta de los tapatíos favoreció al vocablo estándar "moreno" (78\%); en cambio, la voz arcaica "prieto" apenas alcanzó 19\% de frecuencia, aunque esta palabra es de uso común en la mayoría de las zonas de Hispanoamérica, según Moreno de Alba (1992: 51 y 64). Hubo sólo una incidencia de "negro". En el caso de Madrid los datos obtenidos señalan que hay cierta similitud en cuanto a la preferencia léxica, puesto que $70.59 \%$ de los informantes madrileños empleó "moreno" o "morenito". Sin embargo, con respecto al uso de "negro" se presentó una cifra porcentual (23.53\%) más alta que la que imaginábamos, quizá por alguna confusión de los informantes con el color de la raza. En cuanto a la variable de sexo, ni en Guadalajara ni en Madrid hubo una diferencia significativa.

Al referirse a una persona de pelo dorado, el vocablo más generalizado en el español estándar probablemente es "rubio", cuyo empleo está registrado al menos en Madrid, Managua, La Habana, Santo Domingo, San Juan, Quito, Santiago y Buenos Aires (Moreno, 1992: 129). En México una de las formas más usuales para designar a dicha persona quizá sea "güero".

MÉXICO Y LA CUENCA DEL PACÍFICO 169 
Entre los jóvenes tapatíos, con sorpresa, "rubio" fue la palabra predominante (65\%), mientras que el vocablo "güero" apenas alcanzó 32\%. Esta variación/rubio/-/güero/ coincide en mayor o menor grado con la de/blanco/-/güero/ que se observó antes. Entre los jóvenes madrileños "rubio" es la palabra generalizada, lo cual justifica la cifra de $84.37 \%$ que se obtuvo en nuestras investigaciones. En relación con la variación según el sexo, no se presentó ningún indicio distintivo de ambos sexos ni en Guadalajara ni en Madrid.

\section{7. /gordo/-/delgado/}

Con respecto al concepto de una persona con sobrepeso, la voz normativa puede ser "gordo". Según nuestras investigaciones, en Guadalajara el vocablo más preferido también fue "gordo" (54\%). Le sigue el término médico "obeso" (30\%). En la ciudad de Madrid se registraron cifras similares a las de Guadalajara: "gordo" o "gordito" ocupó 58.14\% y "obeso" 13.95\%, cuyo porcentaje fue un poco menor que el de los tapatíos. Estos dos vocablos parecen ser comunes en ambos continentes. Es interesante observar que $18.60 \%$ de los informantes madrileños utilizó "rellenito" - así en diminutivo- que tal vez se deba a cierto afecto que sientan los hablantes por los "gordos", aunque en Guadalajara no se registró ningún caso con dicha palabra. Las demás expresiones o palabras parecen ser de menor importancia, en tanto no existen más de dos incidencias en cada caso.

Para la variable de sexo en Guadalajara se presentó cierta diferencia: 60\% de los hombres usó "gordo" o "gordito", mientras que $40 \%$ de las mujeres aceptó ese uso. En cambio, para "obeso" hubo una tendencia contraria: $64 \%$ de frecuencia en las mujeres contra 36\% en los hombres. Así pues, las tapatías prefieren el uso del término médico, tal vez porque se preocupan más por su aspecto físico. En los informantes madrileños no encontramos ninguna variación de acuerdo con el sexo ni en "gordo" ni en "obeso", pero en el uso de "rellenito" sí hubo cierta diferencia debido a que seis mujeres acudieron a dicha palabra y sólo dos hombres la pronunciaron.

Para referirse a una persona con menos peso que el normal, el vocablo estándar sería "delgado". Según el resultado de nuestras investigaciones, en el habla de Guadalajara solamente hubo 35\% de frecuencia a favor de "delgado". Por otra parte, "flaco" fue la palabra dominante (56\%), cuya tendencia coincide totalmente con la afirmación de Buesa (Buesa, 1992: 218). Este fenómeno resultó viceversa en Madrid; en otros términos, el adjetivo "delgado", "delgaducho" o "delgadito" fue aceptado por $46.15 \%$ de los informantes, mientras que "flaco", "flacucho" o "flaquito" por sólo $33.33 \%$. Dicho resultado coincide con el estudio de Kany, quien menciona sobre la coincidencia del uso americano con "[...] localismos de ciertas regiones españolas (especialmente Andalucía, Extremadura, Asturias, o Cataluña”, pero no con los de Madrid (Kany, 1969: 6).

La variable de sexo tuvo cifras porcentuales significativas. Las mujeres tapatías usaron más "delgado" (75\%) que los hombres (25\%). Por otra parte, el vocablo "flaco" fue favorecido por $68 \%$ de los hombres de Guadalajara y por $32 \%$ de las mujeres. Es importante mencionar que en este parámetro sociolingüístico el resultado obtenido en Madrid coincidió con el de Guadalajara; es decir, "delgado" fue favorecida por $66.67 \%$ de los hombres contra $33.33 \%$ de las mujeres. Asimismo, "flaco" fue predominante en los hombres madrileños (61.54\%) contra las mujeres (38.46\%). 
Al parecer el comportamiento verbal de los hombres es —en general— más bromista o humorístico, porque "flaco" se refiere a la idea más exagerada de "gordo" (Moliner, 1979b: 1313).

\section{8. /alto/-/bajo/}

Si la estatura de una persona es mayor que la del promedio, la palabra adecuada es "alto", y "bajo" en caso contrario. De acuerdo con el corpus obtenido, la palabra predominante en el caso de los hablantes tapatíos fue "alto" con cerca de $85 \%$ de frecuencia. Le siguen "jirafón” y "jirafota", derivadas de "jirafa". Los demás vocablos registrados en Guadalajara fueron "larguchón" y "grande", cada uno con una incidencia. En Madrid el resultado fue similar. Se obtuvo $65.71 \%$ de frecuencia para "alto" o "altote". Le siguen en importancia "gigante", "grande" o "super-grande" y "tocho". ${ }^{10}$ Con respecto a la variable de sexo, no se presentó ninguna preferencia léxica ni en Guadalajara ni en Madrid. En este sentido, cuando predominan las palabras estándares o cultas existe más igualdad lingüística entre hombres y mujeres.

En el habla de los jóvenes tapatíos se registró "bajo" o "bajito" con $28 \%$ de frecuencia. Sin embargo, 57\% de los informantes tapatíos usó "chaparro" o "chaparrito". Nuestro resultado coincide el de Moreno de Alba (1992: 130), ${ }^{11}$ quien afirma que dicho vocablo se difunde no sólo en México, sino también en algunas partes de Centroamérica. La palabra "grande" tuvo los antónimos siguientes: "pequeño" (8.6\%) y "enano" (5.7\%). En cambio, los madrileños mostraron otra preferencia: utilizaron "bajo" o "bajito" con $65 \%$ de frecuencia, luego "enano" o "enanito" con 15\% y "pequeño" o "pequeñín" con 5\%. Lo más interesante es que $10 \%$ de los jóvenes madrileños, aunque sea un porcentaje menos significativo, haya acudido al uso del vocablo "tapón" (Grosschmid y Echegoyen, 1998: 517): "eres como un tapón de botella" (inf. 25) ${ }^{12}$. De hecho, esta voz no se reconoce en América en sentido de "bajo", pero en España sí se oye. De ahí que entre las dos ciudades se presente cierto regionalismo o preferencia regional en torno al concepto de una persona "de menor estatura que la normal”.

En lo que se refiere al aspecto sociolingüístico, la variación léxica según el sexo fue la mínima; esta tendencia resultó común en ambas ciudades. Lo único que caracteriza al habla tapatía femenina tal vez sea el uso del diminutivo "-ito": "chaparrito" (dos casos) y "bajito" (cuatro casos).

\section{9. /guapo/-/feo/}

Los jóvenes tapatíos usaron "guapo/guapa" con más frecuencia (54\%). La forma "guapote" que utilizó una informante, a pesar del uso del aumentativo "-ote", en México no contiene ningún valor despectivo, sino más bien enfático. Sigue "bueno/buena" o "buenísima" con 17\%, aproximadamente: "está buena" cuya frase se usa popularmente en sentido de "atracción física o externa de una persona”. A nuestro parecer, "bueno/buena", además de ser un popularismo o vulgarismo, se emplea con un matiz más directo en cuanto a la atracción sexual (León, 1984: 41). Entre otros vocablos o expresiones también hubo dos incidencias de "buena personalidad" y "papacito", ${ }^{13}$ respectivamente. Con respecto al habla de los jóvenes madrileños, podremos decir que hay algo en común con los rasgos que se presentan en Guadalajara. Sorprendentemente, "bueno/buena" se usa en Madrid con más frecuencia (35\%); es interesante que tres informantes (inf. 8, inf. 19 e inf. 20) ${ }^{14}$ hayan empleado dicho 
calificativo en combinación con el sustantivo "tío/tía": "tío bueno" o "tía buena". La palabra "guapo/guapa" obtuvo menor frecuencia (27.50\%). Las demás palabras o expresiones registradas quizá no tengan importancia estadística, pero es conveniente mencionar que hubo un caso de "majo" que significa que "en su porte, acciones y vestidos afecta un poco de libertad y guapeza, más propia de la ordinaria" (RAE, 2001: 1421): “¿Qué majete!", pues el último vocablo supuestamente ha sido, hasta cierto punto, común en España. Este resultado sorprendente quizá se deba - aunque por el momento no dispongamos de datos científicos-al posible desuso de dicha voz en las generaciones jóvenes.

$\mathrm{Al}$ hablar de la variable de sexo, en términos generales, no hubo mucha variación, excepto en el caso del calificativo "bueno/ buena". En el habla juvenil de Guadalajara cuatro hombres prefirieron este uso frente a dos mujeres; en Madrid ocho hombres lo utilizaron frente a seis mujeres. Esta diferencia, común en ambas ciudades, indica tácitamente que el habla masculina tiende a acudir con más frecuencia al vulgarismo o popularismo.

En lo que se refiere al antónimo de "guapo" la palabra predominante fue "feo", tanto en Guadalajara como en Madrid, cuya frecuencia fue de $53 \%$ en la tierra tapatía y $60 \%$ en la última ciudad. El uso de los demás vocablos es esporádico debido a una o dos incidencias en ambos lugares. Sólo quisiéramos mencionar algunos casos que nos parecieron que son de uso regional. En Guadalajara hubo dos incidencias de "gacha" ${ }^{5}$ y "fachosa", ${ }^{16}$ una incidencia de "guandaja"17 y una "del nabo". ${ }^{18}$ En Madrid algunas expresiones que nos llamaron la atención son "un cayo malayo"19 y "mogollón de fea", que fueron dichas por los informantes masculinos. La variación según el sexo parece ser de menor importancia en ambas ciudades, pero quizá los hombres se expresaron con más exageración o ironía que las mujeres (Kishi, 2002: 87), aunque las incidencias no sean cualitativas.

\section{0. /calvo/-/cabelludo/}

$\mathrm{Al}$ referirse a una persona "que ha perdido el pelo de la cabeza" (RAE, 2001: 406), los jóvenes de Guadalajara emplearon "calvo" y "pelón", los términos predominantes (52\% y $48 \%$, respectivamente). En Madrid parece que "calvo" es el vocablo generalizado (80\%). Por otra parte, no se registró ningún caso de "pelón", pero hubo una incidencia de "pela(d)o". Cabe mencionar, de acuerdo con nuestros datos, que "pelón" parece ser la palabra preferida por los jóvenes tapatíos. También algunos madrileños (8.57\%) utilizaron "entradas": "tiene entradas". Sobre la variación según el sexo, en el habla juvenil de la ciudad tapatía sí existe cierta preferencia léxica: seis hombres (38\%) y diez mujeres (62\%) acudieron al vocablo académico "calvo", y al contrario diez hombres (67\%) y cinco mujeres (33\%) usaron "pelón". Como éste tiene un matiz de uso familiar (Blecua, 1998: 126), es muy probable que los hombres lo hayan preferido en lugar de "calvo". En el habla juvenil de Madrid, respecto al término que acabamos de mencionar, no se presentó ninguna fluctuación léxica de acuerdo con el sexo, pues catorce hombres y catorce mujeres lo usaron indistintamente.

Los supuestos antónimos de "calvo" o "pelón" serían "peludo" y "cabelludo". Al menos $55 \%$ de los jóvenes tapatíos prefirieron usar "greñudo", la cual se refiere a una persona con "cabellera revuelta y mal compuesta”, según la Real Academia Española (RAE, 2001: 1157). Sin embargo, la norma lingüística mexicana parece ser un 
poco distinta a la española, pues la "greña" en México se trata de la "melena o pelo largo, enmarañado y descuidado" (Lara, 1996: 469). La voz de "peludo" alcanzó solamente $23 \%$, y no se encontró ningún caso de "cabelludo". En Madrid el vocablo predominante fue "peludo" con $58.62 \%$ de frecuencia. Le sigue en importancia "melenudo" con $10.34 \%$ y no presentó ningún caso con el calificativo de "greñudo", con excepción de "tiene greñas". Además, ni los madrileños utilizaron "cabelludo". De todos modos, la expresión de dicho concepto se realiza con cierto regionalismo en cada ciudad. La variable de sexo, en este caso, no influye sobre el uso de los mencionados vocablos en ninguna zona.

\section{1. /rizo/-/lacio/}

Para referirse a una persona con pelo "que tiende a rizarse naturalmente" (RAE, 2001: 1979), una de las voces más comunes en los países de habla hispana posiblemente sería "rizado". A pesar de esta tendencia, en la ciudad de Guadalajara el uso apenas alcanzó 10\%; tampoco hubo incidencias de "rizo". Los jóvenes tapatíos (63\%) prefirieron usar "chino" 20 o "chinito", cuyo resultado coincide totalmente con la afirmación de Moreno de Alba (1992: 118-119). Las demás expresiones registradas se usaron esporádicamente. En cambio, la respuesta predominante de los madrileños fue "rizado" (67.64\%), como se había esperado. Le sigue "rizo(s)" o "ricito" (17.65\%). Quizá sea interesante mencionar que dos informantes femeninas, aunque las incidencias no sean significativas, utilizaron el nombre propio "Kelvin": ${ }^{21}$ "pareces un Kelvin"; parece que no es usado por la forma del pelo, sino analógicamente por la de la barba, ya que tenía su pelo un poco ondulado. De acuerdo con estos datos, los madrileños prefieren "rizado" y los tapatíos "chino". En cuanto al aspecto sociolingüístico según el sexo, ni Guadalajara ni Madrid mostraron una variación importante.

En Guadalajara el supuesto antónimo de las mencionadas voces fue "lacio" (91\%). Hubo sólo una incidencia (3\%) de "liso", cuyo significado se puede aplicar al "cabello", según Moliner (1979: 266). En Madrid los jóvenes prefirieron "liso" (77.14\%) más que "lacio" (8.57\%). Así que en estos conceptos/rizo/-/lacio/ presenta una regionalización léxica en ambas ciudades. En relación con la diferencia según el sexo, no hubo ninguna fluctuación ni en Guadalajara ni en Madrid.

\section{2. /ojos grandes/-/ojos pequeños/}

Sobre una persona con ojos de buen tamaño y atractivos, $77.6 \%$ de los jóvenes tapatíos acudió a la construcción /ojos + calificativo/, tal vez a causa de la escasez del calificativo que corresponde a esa naturaleza. Las más importantes fueron "ojos bonitos" (doce casos) y "ojos grandes" (nueve casos). Los demás adjetivos registrados son esporádicos: "pizpiretos”, "tapatíos", "redondos”, "bellos", "hermosos", "lindos", "coquetos" y "expresivos", respectivamente. El uso del sustantivo "ojo" con aumentativo fue poco frecuente, ya que 15\% de los tapatíos usó "ojón” y sólo 5\% “ojazos". Curiosamente, esta tendencia fue contraria en Madrid: hubo apenas $11.11 \%$ de frecuencia en "ojos grandes" y "ojos bonitos", respectivamente, mientras que "ojazo(s)" fue el vocablo que predominó con $74.07 \%$. De ahí que en este caso también se observe cierta preferencia tanto léxica como morfosintáctica en cada ciudad. Respecto a la diferencia según el sexo, prácticamente no se han encontrado ejemplos significativos. Sólo es probable que en las mujeres, en especial las tapa- 
tías, exista más variación léxica en cuanto a los calificativos.

$\mathrm{Al}$ referirse al concepto contrario, se presentó un fenómeno similar al caso anterior. Es decir, 88\% de los tapatíos prefirió acudir a la construcción /ojos + calificativo/. Los calificativos más usados son "pequeños" (30\%), "chiquitos" o "chicos" (20\%) y "feos" (13\%), entre otros. También hubieron algunos casos en que prefirieron usar palabras menos fuertes o dañinas: "normales" (7\%) y "regulares" (3\%, aproximadamente). El uso del diminutivo "-ito" como en "ojitos" fue realmente esporádico en el habla juvenil de Guadalajara, ya que dicha frecuencia apenas alcanzó 10\%. Ahora bien, el resultado obtenido en Madrid fue distinto. El uso de los diminutivos "-ito" y "-ín": "ojitos" y "ojines", tuvo cierta importancia porcentual, ya que $37.14 \%$ de los jóvenes madrileños se expresó de esa manera. Con respecto al uso de /ojos + calificativo/, lo utilizó $60.5 \%$ de los informantes madrileños, aunque con menos frecuencia que los tapatíos. El adjetivo de mayor uso, entre otros, fue "pequeños" o "pequeñitos", cuyo porcentaje alcanzó 40\%. En la variable de sexo no encontramos ninguna diferencia cualitativa entre ambas ciudades; sin embargo, se ha observado que en el habla femenina de las dos zonas metropolitanas el uso de los diminutivos es más vigoroso. Podemos citar "chiquitos" (tres mujeres contra un hombre) y "ojitos" (dos mujeres contra un hombre) en Guadalajara; "ojitos" y "ojines" en Madrid (diez mujeres contra tres hombres). Nuestro resultado puede estar respaldado por la hipótesis de SilvaCorvalán. ${ }^{22}$

\section{3. /nariz alta/_/nariz baja/}

Cuando se trata de la nariz de una persona de tamaño mayor, los jóvenes tapatíos emplean el vocablo "narizón" (87\%). Hubo un caso (3\%) de "narigón". En Madrid, de la misma manera pero con mayor variación morfológica, el uso de los aumentativos fue de $79.99 \%$, entre los cuales están registrados "narizota" (31.43\%), "narizón" (20\%), "narigudo" (14.28\%), "narigón" (8.57\%) y "narizudo" (5.71\%). La primera palabra parece referirse a la "nariz" y las demás a la "persona con dicho rasgo". Quizá sea conveniente añadir que algunos jóvenes madrileños usaron vocablos populares: "napia(s)" ${ }^{23}$ y "tocha"24, por ejemplo, como en "tiene napias" y "ipedazo de tocha que tienes!". En ninguna ciudad se presentó la forma "nariz alta".

Para referirse a la idea contraria, la forma más preferida por los jóvenes tapatíos fue /nariz + calificativo/. Los calificativos o sus equivalentes registrados son "pequeña" (36\%), "chiquita" (7\%), "respingada" (3.5\%) y "de pizca" (3.5\%). La voz "chato" fue utilizada por $21 \%$ de los tapatíos, si bien se oye quizá con más frecuencia. Y sólo $11 \%$ de los tapatíos acudió al uso del diminutivo "naricita". Las demás expresiones nos parecen poco importantes. En cambio, los jóvenes madrileños prefirieron la forma "chato" o "chatín" con $45.83 \%$ de frecuencia. Le sigue el uso del diminutivo "naricita" o "varicilla" con $25.50 \%$. La construcción /nariz + calificativo/ fue menos usual en Madrid, ya que $20.83 \%$ de los informantes usó el adjetivo "pequeña" y 4.17\% "aguileña". Aquí tampoco se encontró el uso de "baja". En nuestra investigación no apareció, pues, ningún caso de la dicotomía /alta/-/baja/. Así mismo, hubo variación léxica según el sexo en las dos ciudades.

\section{4. /boca grande/-/boca chica/}

Para el concepto de la boca de una persona de tamaño mayor, los jóvenes tapatíos 
usan más el aumentativo "-ón” (52\%) que otros: "bocón” (39\%), "jetón” (8\%) y "hocicón” (5\%, aproximadamente), si bien la primera también puede significar "hablador" o "mentiroso". Por lo menos 40\% de los tapatíos entrevistados acudió a la construcción /boca + calificativo/. Los calificativos registrados son "grande" (28\%), "carnosa", "ancha”, "de sandía" y "de pescado" (3\%, respectivamente). Asimismo, hubo un caso de "labios gruesos". Ahora bien, la forma preferida por los jóvenes madrileños fue "bocaza(s)" con 51.51\% de frecuencia; lo curioso es que la RAE no admite su uso con valor del 'tamaño de la boca', sino que se trata de la "persona que habla más de lo que aconseja la discreción" (RAE, 2001: 330), a lo cual se referían en la entrevista tres informantes (inf. 15; inf. 20; inf. 30 ${ }^{25}$. Le sigue en importancia la forma /boca + calificativo/. Los calificativos o sus equivalentes registrados son "buzón" (15.15\%), "grande" (12.12\%), "chata" (3.03\%), "ancha" (3.03\%), "caballo" (3.03\%) y "chancla" (3.03\%), y algunos de los cuales como "buzón”, "caballo" y "chancla" podrán considerarse del uso humorístico. También hubieron dos casos con "labio(s)": "labios gordos" y "labio de negra". En resumen, los jóvenes de ambas ciudades prefirieron expresarse con aumentativo; en otras palabras, los tapatíos prefirieron "bocón" y los madrileños, "bocaza(s)". Respecto a la diferencia lingüística según el sexo, no hubo nada significativo.

Como expresiones antónimas de las que se acaban de mencionar, la mayoría de los jóvenes de Guadalajara prefirió utilizar la construcción /boca + calificativo/: "boca chica" o "chiquita" (50\%), "boca pequeña" (27\%) y "boca normal" (3\%, aproximadamente). Hubo tres casos de "labios": "labios chicos", "labios delgados" y "sin labios". Encontramos únicamente dos casos del uso del diminutivo: "boquita" y un caso de la combinación "boquita delgadita"; es decir, dicho empleo alcanzó apenas 10\% de frecuencia. En Madrid el uso de los diminutivos "boquita" o "boquilla" fue más activo (29.63\%). Esta diferencia quizá se deba al distinto uso de los diminutivos en cada zona, pues éstos se usan en España para referirse a la "disminución de tamaño en el objeto designado" (RAE, 2001: 825), mientras que en México, además de dicha función original, se usan frecuentemente con valor de "afecto y respeto" (Lara, 1996: 354). De todos modos, la mayoría de los jóvenes madrileños también acudieron al uso de "boca pequeña" o "pequeñita" (33.33\%); "boca" o "boquita de piñón" (18.52\%); "boca chiquitita" o "chica"; entre otros. Es interesante observar que la forma "boca" o "boquita de piñón" se oyó solamente de boca de los madrileños.

Con respecto a la variación léxica según el sexo, no encontramos mayor diferencia, excepto en el caso de "boca pequeña" o "pequeñita" en Madrid; se registraron dos incidencias en los hombres contra siete en las mujeres. Esto puede ser por una simple preferencia de las informantes madrileñas.

\section{5. /busto grande/-/busto chico/}

Para referirse a una mujer con busto de mucho volumen, aproximadamente 59\% de los jóvenes tapatíos prefirió usar la voz "chichona"(RAE, 2001: 526) del probable origen nahua. ${ }^{26}$ Dicho vocablo, según nuestras observaciones, parece ser bastante generalizado dentro de la norma lingüística mexicana. Las demás palabras o expresiones se registraron de manera esporádica: "pechugona" con tres incidencias; "voluminosa" y "busto grande" con dos incidencias respectivas; entre otras. 
En el habla de los jóvenes madrileños la palabra "tetona" fue una de las más utilizadas con $32.26 \%$. De la misma manera, se presentó con cierto vigor "tetuda" con $19.35 \%$, y hubo un caso también con el sustantivo "tetas": "tiene grandes tetas". La voz "teta" ocupa $54.83 \%$ en Madrid, por lo tanto, es una de las expresiones más preferidas para designar a una mujer que tiene la mencionada naturaleza física. El vocablo "pechugona" puede ser de cierta importancia, pues su uso llegó a $25.81 \%$. El empleo de la expresión "busto grande" (sólo una incidencia) es esporádico también en esta ciudad europea.

En la cuestión de la variable de sexo, aunque solamente con valor cuantitativo, se encuentra cierta variación en el habla de Guadalajara; en el uso de "chichona" parece existir más preferencia de parte de los hombres (con trece incidencias) que de las mujeres (con seis incidencias), probablemente por la tendencia masculina a expresarse de manera más directa.

En Guadalajara el antónimo del vocablo fue "plana" con $40 \%$ de frecuencia. Le sigue "busto" con aproximadamente $22 \%$ : "busto pequeño". No creemos que los demás casos sean significativos estadísticamente, pero debemos advertir que hay algunos casos con cierto valor humorístico o burlesco: "nadadora".

El uso predominante en los jóvenes madrileños fue también "plana" con 55.88\%. En el empleo humorístico los vocablos "plancha" y "tabla" quizá sean los más importantes: "tabla de planchar", "es una tabla", entre otros. Al hablar de la variación léxica, parece haber una ligera tendencia con el vocablo "plana", ya que tanto en Guadalajara como en Madrid los hombres lo usaron con más frecuencia que las mujeres: ocho incidencias en los hombres contra cuatro en las mujeres (en Guadalajara); once incidencias en los hombres contra ocho en las mujeres (en Madrid).

\section{6. /vientre grande/-/vientre chico/}

Para designar a una persona con vientre voluminoso, los informantes tapatíos prefirieron la voz "panzón" con $56 \%$ de frecuencia, cuya variación entre ambos sexos fue prácticamente nula. De acuerdo con algunos casos que tienen el mismo lexema de "panza", como "panza de borracho", "panza de cervecero", entre otros, el uso de las expresiones derivadas de "panza" alcanza $71 \%$. De ahí que el vocablo "panza" pueda ser bastante generalizado en México, al menos entre los jóvenes de Guadalajara. En cambio, el uso de "panza", "panzón" y "panzudo" en Madrid no resultó tan común, puesto que apenas llegó a 20.51\%. Por otra parte, las expresiones predominantes entre los jóvenes madrileños son "barriga" y sus derivadas: "barrigón" y "barrigudo", cuya cifra porcentual fue de $38.46 \%$ en total. Tan sólo $12.82 \%$ de los informantes peninsulares también utilizó "tripa", "tripita", "tripón” y "tripudo". Quizá sea conveniente mencionar también que, aunque estadísticamente de menor importancia, hubo dos incidencias con "Homer" ${ }^{27} \mathrm{Y}$ en las dos ciudades no hubo ninguna respuesta con "vientre".

Para referirse al concepto contrario, $46 \%$ de los informantes tapatíos utilizó el calificativo "delgado" o "delgadito". Le siguen "flaco" con $14 \%$ de frecuencia y "esbelto" con 9\%. Estas palabras, aunque no indiquen de forma directa el estado físico del vientre, pueden designar a aquellas personas con dicho rasgo físico. Las demás expresiones dichas por los tapatíos quizá no sean importantes estadísticamente; de hecho, las expresiones con algún lexema de "panza", "vientre" o "estómago" fueron 
esporádicas: "despanzado", "sin panza", "panza de lavadero", "vientre plano" y "estómago de lavadero". Ahora bien, en el habla juvenil de los madrileños el resultado que se obtuvo en las entrevistas es similar al de Guadalajara: $30.77 \%$ de los madrileños usó "delgado", "delgadillo" o "delgaducho"; y 17.24\% empleó "flaco". En Madrid no se registró ningún caso de "panza", pero algunos informantes acudieron al uso de "tripa": "tripa plana", "no tiene tripa" y "vientre plano". Es interesante que se hayan observado dos incidencias con "chocolate": "tabla de chocolate", cuyo uso aparece posiblemente por analogía física con los "cuadritos". ${ }^{28}$

En cuanto al aspecto sociolingüístico, sólo cuatro mujeres tapatías prefirieron usar "delgado" contra once hombres. Asimismo "flaco" fue el calificativo que los hombres tapatíos prefirieron, aunque sólo fueran cinco informantes. La situación lingüística en Madrid coincide con dicha tendencia, ya que cinco mujeres madrileñas prefirieron el uso de "delgado" contra siete hombres; además, sólo cinco informantes masculinos usaron "flaco". No podemos decir que estos datos sean cualitativos, sino que es una realidad lingüística cuantitativa.

\section{7. /piernas gordas/-/piernas delgadas/}

Para referirse a una persona con las pernas llenas, en Guadalajara fue predominante el uso de "piernudo" (67\%), sin que se presente variación alguna según el sexo. También hubo dos casos que utilizaron la forma con el aumentativo "piernón”. Los informantes que acudieron al empleo de la construcción / piernas + calificativo/ fueron pocos (15\%), aproximadamente: "piernas gordas", "piernas con chamorrito", "pier- nas de jamón”, entre otras. En Madrid el resultado obtenido fue algo contrario: el uso del calificativo "piernudo" fue mucho menor de lo que nos imaginábamos, porque hubo sólo una incidencia. El empleo de los aumentativos también fue esporádico: "piernazas" y "piernotas". La forma que prefirieron los jóvenes madrileños es /piernas + calificativo/, la cual llegó a 57.69\%. El adjetivo más usado es "gordas" o "gorditas" con diez incidencias; no creemos que los demás calificativos: "rellenas", "rechonchas" y "grandes" sean importantes. Como expresiones humorísticas quizá podamos citar "tiene buenas jamonas" o "buenos jamones", ${ }^{29}$ entre otras. Con respecto al sexo, al igual que en el habla tapatía, no hubo nada distintivo.

En ambas ciudades hubo más variación léxica con relación a los antónimos. La mayoría de los jóvenes de Guadalajara acudió a la construcción /piernas + calificativo/ con $71 \%$ en total, en la cual destacó la forma "piernas flacas" con diez incidencias. Le siguen los calificativos o sus equivalentes: "delgadas", "de popotitos" y "secas"; los demás casos son realmente escasos, pero quizá sea conveniente citarlos: "de pollo", "de caña", "de palo", "huesudas" y "fláccidas". El uso de algunas palabras como "popotitos", "pollo", "caña” y "palo" refleja seguramente el sentido de humor que tienen muchos mexicanos. No encontramos el uso de los diminutivos en el sentido de la disminución de tamaño. Ahora bien, en Madrid la preferencia por/piernas + calificativo/ puede ser menor, pues su uso alcanzó apenas 30.77\% en total. Los calificativos o sus semejantes que se registraron en nuestra investigación son: "delgadas" o "delgaditas", "pequeñas" o "pequeñillas", "de palo" y "huesudas". El empleo del diminutivo "piernecillas" tampoco fue frecuente (11.54\%). Las demás expresiones son menos importantes en cuanto 
al número de incidencias; sin embargo, es interesante mencionar algunas con uso humorístico: "tiene piernas como palillos"; "tiene unas patillas"; "patas de alambre"; entre muchas otras. Los jóvenes madrileños mostraron también el humorismo lingüístico al menos en este concepto.

\section{7. /pies grandes/-/pies pequeños/}

Para designar a una persona que tiene pies de buen tamaño, los jóvenes tapatíos utilizaron predominantemente el vocablo "patón" que alcanzó 74\% de frecuencia; sin embargo, hubo un caso con el adjetivo "patudo", por lo cual en el habla tapatía, al menos entre los jóvenes, "patón" parece ser una forma estandarizada. Podemos agregar que se registró $23 \%$ de frecuencia de la construcción /pies + calificativo/: "pies grandes" y "pies normales". En Madrid fue preferida dicha construcción con $50 \%$ de frecuencia: "pies grandes", "pies de payaso" y "pies anchos".

El uso de las derivaciones de "pie" fue realmente esporádico: "piezazos", "piezones" y "piezudo". El empleo hasta cierto punto común entre los jóvenes madrileños fue de "barcas" con $26.67 \%$, cuyo vocablo quizá pueda considerarse como un regionalismo de esta zona peninsular porque no se oye en la tierra tapatía. Otro caso similar al mencionado término, semánticamente, es "canoa". El uso de "peanas" ${ }^{30}$ como en la frase "iqué peanas tienes!" posiblemente es de carácter regional y popular en Madrid y algunas partes de la Península.
Con relación al antónimo 74\% los jóvenes tapatíos prefirió usar la forma /pies + calificativo/; es decir, $42 \%$ en "pies chicos" o "chiquitos"; $26 \%$ en "pies pequeños"; un caso para "pies de llavero" y "pies de Cenicienta". El uso del diminutivo "-ecito" o "-ececito": "piecito(s)" y "piececito", no fue muy relevante, ya que la frecuencia alcanzó 16\%. Las demás expresiones no nos parecen importantes. En esta ciudad mexicana no encontramos ningún fenómeno valioso que variara de acuerdo con el sexo. El lenguaje juvenil de Madrid, en este caso, coincide de cierto modo con el de Guadalajara, puesto que $70.37 \%$ de los informantes madrileños también acudió al uso de /pies + calificativo/. Los calificativos usados son "pequeños" o "pequeñitos" (48.15\%), "chiquitajos", "finos", "estrechos", "normales", "de mujer" y "de muñeca". El uso de los diminutivos "piececitos" y "piececines" también fue algo importante, porque obtuvo $29.63 \%$ de frecuencia y en el cual hubo más incidencias en el habla femenina: seis incidencias contra dos en el habla masculina. Sin embargo, este resultado puede ser simplemente cuantitativo.

\section{Conclusión}

De acuerdo con nuestra investigación, las voces o expresiones que presentan cierta diferencia o contraste entre ambas ciudades son: /encuerado/ $(\mathrm{G})$ - /en bolas; en pelotas/ (M); /güero/ (G) - /pálido/ (M); /bocón/ (G) - /bocazas/ (M); /chichona/ (G) -/tetona; 
tetuda/ (M) y /patón/ (G) - /barcas/ (M). ${ }^{31}$ En otras palabras, éstos podrían considerarse como regionalismos absolutos en principio con el mismo significado. Como regionalismos parciales, se encontraron en Guadalajara /prieto/, /güero/, /chaparro/, /pelón/, /greñudo/ y /chino/, los cuales se desconocen en la ciudad peninsular. De la misma manera, encontramos preferencia por /barrigón, barrigudo; barriga/ sólo en los jóvenes madrileños.

Además de dicho fenómeno, no podemos dejar de lado el relativismo. En Madrid existe mayor preferencia por /negro/, /bajo/, /peludo/, /rizado/, /ojazos/ y la construcción /piernas + adjetivo/ que en Guadalajara. Por otra parte, los jóvenes tapatíos prefrieron usar /lacio/, la forma /ojos + adjetivo/, /narizón/ y /panzón/, respectivamente, aunque en Madrid hubieron algunas incidencias. Este fenómeno, en términos sociolingüísticos, puede ser cuantitativo.

El uso del diminutivo, en sentido estricto, es más vigoroso en Madrid, puesto que en México los diminutivos se usan frecuentemente, más bien, con valor afectivo. Asimismo, en la misma ciudad existe mayor variedad de los diminutivos que en Guadalajara: "-ito", "-ecito", "-ececito", “-ecino", "-ín”, "-illo" y probablemente "-ucho", cuyo sufijo despectivo semánticamente podría considerarse como aumentativo. Al igual que en el caso de los diminutivos, en $\mathrm{Ma}$ drid parecen ser también más usuales los aumentativos: “-ón/-ona”; “-azo/-aza”; “ota" y "-udo", mientras que en Guadalajara sólo “-ón/-ona” y “-udo".

En lo que se refiere a la variación sociolingüística, en especial según el sexo, realmente no se ha presentado mucha diferencia, excepto en algunos casos. En ambas ciudades "delgado" es preferido por las mujeres, mientras que "flaco" por los hombres. Independientemente, en Guadalajara, como ya hemos visto en otros trabajos, los hombres mostraron cierta preferencia por "gordo", y las mujeres por "obeso"; las mujeres por "calvo" y los hombres por "pelón”. En Madrid las mujeres prefirieron el uso académico "desnudo", mientras que los hombres acudieron al empleo popular de "en bolas" y "en pelotas".

Las demás expresiones o palabras pueden ser comunes en las dos ciudades o quizá en muchas regiones de habla hispana; sin embargo, debemos estar concientes de cierta regionalización lingüística en el lenguaje hablado, al menos entre los jóvenes, quienes normalmente acuden con más frecuencia al uso popular. Esto puede suceder no sólo a nivel léxico, sino también a otros niveles lingüísticos. nู?

\section{Notas}

1 Uno de sus trabajos más importantes puede ser Labov (1966).

2 Hemos seleccionado dieciocho ítems: /desnudo/, /mojado/, /sucio/, /sano/, /cansado/, /gordo/-/delgado/, /alto/-/bajo/, /blanco/-/moreno/_/rubio/, / guapo/-/feo/, /calvo/-/cabelludo/,/rizado/_lacio/, /ojos grandes/-/ojos pequeños/, /nariz alta/-/ nariz baja/, /boca grande/-/boca chica/, /busto grande/-/busto chico/, /vientre grande/-/vientre chico/, /piernas gordas/-/piernas delgadas/ y /pies grandes/-/pies pequeños/.

3 Moreno de Alba (1992: 102) comenta que es una voz andaluza. Este vocablo se puede oír también en Andalucía, Extremadura, Cuba, República Dominicana, Colombia, Chile y Perú (Grosschmid y Echegoyen, 1998: 248; RAE, 2001: 906; Moliner, 1979b: 1111).

4 Moliner lo registra como el verbo "calarse" que significa 'empaparse' (Moliner, 1979: 459), por lo cual el uso como adjetivo puede ser totalmente aceptable dentro de la norma española.

5 Este vocablo "guarro/a" se refiere coloquialmente a un "hombre sucio y desaliñado" o a una "mujer sucia y desaliñada" (RAE, 2001: 1171).

6 Ya que esta palabra se refiere al "hombre capaz de todo y en cualquier sentido" (De Usandizaga, 1975: 111), es totalmente aceptable el uso con valor de "sano". Además esta voz tiene cierta

MÉXICO YLACUENCADEL PACÍFICO 179 
vitalidad lingüística, al menos en el habla popular, tanto en Jalisco como en muchos otros estados de la República Mexicana (De Usandizaga, 1975: 8).

7 Probablemente es de origen indígena (RAE, 2001: 1174).

8 Estos datos se basan en los comentarios de varios informantes madrileños.

9 En México se refiere a un "mestizo de morisco y blanco" (Grosschmid y Echegoyen, 1998: 28).

10 El uso de esta voz en sentido de "alto" probablemente viene del significado de "garrote", cuyo empleo se conoce en las regiones de Aragón y Salamanca. Aunque aún no esté registrado en Madrid, es posible la difusión de la voz hasta Madrid (Moliner, 1979b: 1329).

11 Esta palabra parece estar difundida hasta las regiones andinas (Grosschmid y Echegoyen, 1998: 156).

12 Francisco Miguel Diez Sanz; 20 años; panadero y estudiante; originario de Madrid.

13 Garza Cuarón comenta que se usa esta voz en sentido de "padre' como "apelativo cariñoso" (Garza Cuarón, Beatriz. El español hablado en la ciudad de Oaxaca, México. México, El Colegio de México. 1987. p. 74). Sin embargo, según nuestras observaciones, se usa también como una expresión de piropo.

14 Inf. 8: Pablo Martín; 18 años; estudiante; originario de Madrid. Inf. 19: Cristina González Cañarero; 20 años; estudiante; originaria de Madrid. Inf. 20: Bieito Flores Lovzao; 20 años; estudiante; originario de Madrid.

15 Parece ser el uso mexicano con valor de "feo o desagradable" (RAE, 2001: 1104).

16 En México se usa en sentido de "mal vestido" (RAE, 2001: 1030). Es totalmente lógico este empleo porque "estar feo" se refiere a lo desagradable en la apariencia física.

17 Significa “descuidado en el vestir". La voz parece ser común en México, al menos en el lenguaje popular de Jalisco (Brambila, 1957: 122).

18 En España no usarían esta voz en este sentido, ya que en esa zona se refiere como argot al "órgano sexual masculino" (León, 1984: 111); últimamente, en México, al menos en el habla juvenil tapatía, parece estar de moda el uso del vocablo en cuestión en sentido de "feo" u "horrible".

19 Coloquialmente se refiere a una "mujer muy fea" (RAE, 2001: 404).

20 En México se refiere al "pelo natural o artificialmente muy rizado" (Lara, 1996:316). Según Lope Blanch, esta voz probablemente tiene origen nahua (Lope, 1979).

21 William Thomson Kelvin fue un físico y mate- mático británico.

22 De acuerdo con Silva-Corvalán, las diferencias lingüísticas según el sexo son más bien cuantitativas que cualitativas (Silva-Corvalán, 2001: 96).

23 En España se trata de la "nariz grande" (Grosschmid y Echegoyen, 1998: 390).

24 El uso tal vez provenga del significado de "garrote" por su forma (Moliner, 1979b: 1329).

25 Inf. 15: José Luis Cruz; 22 años; estudiante; originario de Madrid. Inf. 20 (véase la Nota 15). Inf. 30: Ana Muñón de la Torre; 20 años; estudiante; originaria de Madrid.

26 Etimológicamente es más probable que esta voz se derive de "chichis" que significa "busto o pechos", ya que se puede considerar como una forma abreviada de "chichihualli" (Leander, 1972: 42).

27 Homer Simpson es un personaje de las caricaturas estadounidenses, quien se caracteriza por su panza o barriga grande.

28 Según la respuesta de un informante (inf.22), "porque tiene cuadritos"(Joaquín González; 20 años; estudiante; originario de Madrid).

29 El uso de la voz "jamones" viene indudablemente de la analogía con la "pierna trasera del cerdo". De la misma manera "jamonas" tal vez se considere como una variación de dicha voz, aunque en España coloquialmente se refiere a una mujer "que ha pasado de la juventud, especialmente cuando es gruesa" (RAE, 2001: 1313).

30 Según Grosschmid y Echegoyen, se refiere a "pie" en España (Grosschmid y Echegoyen, 1998: 418).

31 En este caso, "G" se refiere a Guadalajara y "M" a Madrid.

\section{Referencias bibliográficas}

Blecua, J. (dir.) (1998), Diccionario avanzado. Sinónimos y antónimos de la lengua española, Bibliograf, Barcelona.

Brambila, A. (1957), Lenguaje popular de Jalisco, Guadalajara.

Buesa, T. (1992), Léxico del español en América. Su elemento patrimonial e indígena, Mapfre, Madrid.

De Usandizaga, P. (1975), El chingolés, $4^{a}$ edición, B. Costa-Amic, México, DF.

Garza, B. (1987), El español hablado en la ciudad de Oaxaca, México, El Colegio de México, México, DF.

Grosschmid, P. y C. Echegoyen (1998), Diccionario de regionalismos de la lengua española, Ed. Juventud, Barcelona. 
Kany, C. (1969), Semántica hispanoamericana, Aguilar, Madrid.

Kishi, D. (2002), "Variación léxica según el sexo en el lenguaje hablado de los jóvenes tapatíos", en México y la Cuenca del Pacífico, vol. 6, núm. 20, pp. 82-94.

Labov, W. (1966), The Social Stratification of English in New York City, Center for Applied Linguistics, Washington, DC.

Lara, L. (1996), Diccionario del español usual en México, El Colegio de México, México, DF.

Leander, B. (1972), La herencia cultural del mundo náhuatl, SEP, México, DF.

León, V. (1984), Diccionario de argot español, Alianza Editorial, Madrid.
Lope, J. (1979), Léxico indígena en el español de MéxiCo, $2^{a}$ edición, El Colegio de México, México, DF. Moliner, M. (1979), Diccionario del uso del español: A-G, Gredos, Madrid.

- (1979b), Diccionario del uso del español: H-Z, Gredos, Madrid.

Moreno, J. (1992), Diferencias léxicas entre España y América, Mapfre, Madrid.

RAE (2001), Diccionario de la lengua española, 22a edición, Espasa-Calpe, Madrid.

Silva-Corvalán, C. (2001), Sociolingüística y pragmática del español, Georgetown University Press, Washington, DC. 